Editoriais / Editorials

\section{Fator V de Leiden Factor V Leiden}

José M. P. Godoy

São freqüentes as solicitações para que se avaliem pacientes com tromboses periódicas ou em locais incomuns nos sistemas arterial ou venoso. Podem-se detectar fatores desencadeantes óbvios, mas em muitos destes casos há possibilidade da presença de um estado de hipercoagulabilidade não diagnosticado. ${ }^{1}$ Contudo, as dificuldades e limitações adversas encontradas diariamente fazem com que se busque identificar as mais prevalentes numa fase inicial até chegar ao diagnóstico. O fator V de Leiden, descoberto em 1994, é o mais importante fator de risco genético da trombose venosa e trata-se de uma alteração hereditária, autossômica dominante, que interfere na atuação da proteína $\mathrm{C}$, na sua forma ativada, que é um dos fatores reguladores do sistema de coagulação e que atua na inativação proteolítica do fator Va e do fator VIIIa. Esta alteração é decorrente da troca da arginina 506 do fator V por uma glutamina (R506Q) induzindo à resistência da proteína $\mathrm{C}$ ativada, na qual a clivagem e inativação do fator Va é feita de forma insatisfatória, levando-o ao acúmulo e conseqüentemente aumentando o risco de trombose. ${ }^{2,3}$

$\mathrm{O}$ fator $\mathrm{V}$ de Leiden, além de afetar os vasos comuns nos eventos trombóticos, pode atingir locais incomuns do sistema arterial e venoso, associando-se à restrição de crescimento intra-uterino ${ }^{4}$ e o aborto. ${ }^{5}$

Embora o risco de trombose venosa em pessoas homozigotas para a mutação possa aumentar de cinqüenta a cem vezes em relação aos indivíduos normais, muitas delas não desenvolverão a doença. Por outro lado, a associação com outros fatores de risco, como antecedentes hereditários, ou exposição a fatores de risco, especialmente os traumas, cirurgia e gravidez, pode expor ao risco maior de evento trombótico. Portanto, além do tratamento, devem-se avaliar as situações que exigem a prevenção. Os familiares dos portadores devem ser avaliados sobre a presença ou não da trombofilia quando expostos a fatores de riscos.

$\mathrm{O}$ diagnóstico do fator $\mathrm{V}$ de Leiden pode ser realizado de forma indireta por ensaios funcionais da resistência da proteína $\mathrm{C}$ ativada ou de forma direta analisando-se o DNA, porém é importante que se determine a forma homozigota ou heterozigota; neste caso, a análise do DNA é obrigatória.

\section{Referências Bibliográficas}

1. Johnson CM, Mureebe L, Silver D. Hypercoagulable states: a review. Vasc Endovascular Surg 2005 Mar-Apr;39(2):123-33.

2. Arruda VR, Von Zuben PM, Chiaparini LC, et al. The mutation Ala677®Val in the methylene tetrahydrofolate reductase gene: a risk factor for arterial disease and venous thrombosis. Thromb Haemost 1997;77:812-21.
3. Poort SR, Rosendaal FR, Reitsma PH, Bertina RM. A common genetic variation in the 3 '-untranslated region of the prothrombin gene is associated with elevated plasma prothrombin levels and an increase in venous thrombosis. Blood 1996;88:3698-703.

4. Haywood S, Liesner R, Pindora S, Ganesan V. Thrombophilia and first arterial ischaemic stroke: a systematic review. Arch Dis Child. 2005 Apr;90(4):402-5.

5. Krabbendam I, Franx A, Bots ML, et al. Thrombophilias and recurrent pregnancy loss: a critical appraisal of the literature. Eur J Obstet Gynecol Reprod Biol 2005 Feb 1;118(2):143-53.

Prof. Adjunto do Departamento de Cardiologia e Cirurgia Cardiovascular da Faculdade de Medicina de São José do Rio Preto - Famerp - SP - Brasil.

Faculdade Estadual de Medicina de São José do Rio Preto $S P-$ Brasil.

Correspondência para: José Maria Pereira de Godoy Rua Floriano Peixoto, 2950

15010-020 - São José do Rio Preto-SP - Brasil

E-mail: godoyjmp@riopreto.com.br

\section{Duffy: um sistema de grupos sangüíneos com considerável complexidade}

\section{Duffy: a considerably complex blood group system}

Luiz C. Mattos

O interesse contemporâneo pela compreensão do significado dos polimorfismos nos sistemas biológicos e nas populações tem se voltado com especial atenção aos sistemas de grupos sangüíneos humanos. Embora muitos ainda acreditem que não há explicações teleológicas para a presença dos antígenos de grupos sangüíneos nos vertebrados, sem relacioná-los à transfusão e aos transplantes de órgãos sólidos, são crescentes as evidências de que esses aloantígenos exercem importantes funções, atuando como enzimas, como moléculas reguladoras, transportadoras, de adesão celular e também como receptores para microrganismos e outras substâncias. ${ }^{1}$

Desde a descoberta do sistema ABO, mais de 250 antígenos eritrocitários foram descritos e organizados em sistemas, séries e coleções. ${ }^{2}$ Essa diversidade confere aos eritrócitos uma posição de destaque entre as células que expressam grande número de moléculas polimórficas na membrana.

A expressão de alguns sistemas de grupos sangüíneos em outros tecidos, além do hematopoético, parece ser um fator que eleva o nível de complexidade tecidual em seus aspectos moleculares, antigênicos e funcionais, podendo ser relacionada ao tipo e ao padrão de diferenciação celular. ${ }^{3}$ Obviamente, isso atrai a atenção para a compreensão da 
importância biológica e da pressão evolutiva que contribuiu para a criação e para a manutenção desses polimorfismos nos seres humanos.

A clonagem dos genes que controlam a expressão dos antígenos eritrocitários, a caracterização estrutural dessas moléculas e a avaliação da sua expressão tecidual diferencial são avanços de grande importância para o entendimento de muitos aspectos funcionais dos sistemas de grupos sangüíneos. ${ }^{4}$ Diante da diversidade, da complexidade e das potenciais funções inerentes a seus antígenos, os grupos sangüíneos humanos constituem um tema de grande interesse não somente pela importância transfusional, mas também pelas potenciais aplicações em outras áreas tais como antropologia, genética, bioquímica, imunologia, transplantes de órgãos e evolução, dentre outras.

Neste volume, Novaretti e colaboradores apresentam uma revisão sobre o sistema de grupos sangüíneos Duffy. Os autores discutem os aspectos estruturais da proteína FY e mostram resultados recentes obtidos por análise molecular dos genes funcionais e silenciosos do locus FY. Traçam o perfil dos anticorpos desse sistema e comentam sua importância na medicina transfusional e na doença hemolítica perinatal. Além disso, abordam o papel dos antígenos Duffy, também denominados DARC (Duffy Antigen/Receptor for Chemokines), como receptores para o Plasmodium vivax e para a interleucina 8 , dando destaque ao papel biológico resultante da expressão desse sistema em outros tecidos.

O sistema de grupos sangüíneos Duffy é muito mais complexo do que aparenta, quando visto apenas sob a perspectiva sorológica. Como sua presença não se restringe aos eritrócitos, a expressão tecidual diferencial do DARC em indivíduos com fenótipo Fy(a-b-) portadores da mutação GATAbox, confere a esse sistema um nível polimórfico adicional. ${ }^{5} \mathrm{E}$ possível que a presença do DARC em outros tecidos anule quaisquer desvantagens resultantes de ausência nos eritrócitos, preservando assim seu papel funcional. Devido à sua importância para a hemoterapia, o First International Workshop on Blood Group Genotyping recomenda a identificação da mutação GATA-box em pacientes Fy(a-b-) que necessitam de transfusão. ${ }^{6}$

Diante de sua complexidade, não é surpreendente o envolvimento do sistema Duffy em diferentes processos biológicos. Sua participação na resposta inflamatória e na rejeição de aloenxertos renais, contribuindo para a menor sobrevida do enxerto e para o restabelecimento tardio da função renal, tem sido documentada. ${ }^{7}$ A constatação de que os eritrócitos Duffy negativos [Fy(a-b-)] eram resistentes à infecção pelos $P$. knowlesi e $P$. vivax fundamentou a proposição de que a ausência dos antígenos Duffy nos eritrócitos representa um exemplo de processo de seleção natural, especialmente em áreas onde o $P$. vivax constitui o agente indutor da pressão seletiva. Essa resistência parece ter influenciado de maneira acentuada a distribuição dos fenótipos Duffy nas diferentes populações. ${ }^{8}$ A implicação do sistema Duffy como fator de suscetibilidade e resistência à malária também foi recentemente avaliada na Amazônia brasileira. ${ }^{9,10}$

Os estudos realizados nas últimas décadas revelaram a complexidade do sistema Duffy em seus níveis fenotípico, genotípico e tecidual. A ausência de seus antígenos nos eritrócitos parece ter um significante impacto na distribuição das populações humanas nas áreas em que a malária é endêmica. Entretanto, a expressão do DARC em outros tecidos acrescenta considerável complexidade estrutural e funcional, imputanto a esse sistema um importante papel na resposta inflamatória, na rejeição a aloenxertos e, possivelmente, na histocompatibilidade. O sistema Duffy constitui, portanto, um sistema polimórfico que oferece grandes desafios aos pesquisadores não somente pela sua importância acadêmica, mas também pelas potenciais aplicações na medicina.

\section{Referências Bibliográficas}

1. Cartron JP, Colin Y. Structural and functional diversity of blood group antigens. Transfus Clin Biol 2001;8:163-199.

2. Daniels GL, Fletcher A, Garraty G, et al. Blood group terminology 2004: from the International Society of Blood Transfusion committee on terminology for red cell surface antigens. Vox Sang 2004;87(4):304-316.

3. Ravn V, Dabelsteen E. Tissue distribution of histo-blood group antigens. APMIS 2000;108(1):1-28.

4. Logdberg L, Reid ME, Lamont RE, et al. Human blood group genes 2004: chromosomal locations and cloning strategies. Transf Med Rev 2005;19(1):45-57.

5. Chaudhuri A, Polyakova J, Zbrzezna V, Pogo O. The coding sequence of Duffy blood group gene in humans and simians: restriction fragment lenght polymorphism, antibody and malarial parasite specificities, and expression in non-erithroid tissues in Duffy negative individuals. Blood 1995;85:615-621.

6. Daniels GL, van der Shoot CE, Olsson ML. Report of the First International Workshop on molecular blood group genotyping. Vox Sang 2005;88:136-142.

7. Mange KC, Prak EL, Kamoun M, et al. Duffy antigen receptor and genetic suscetibility of African Amerincans to acute rejection and delayed function. Kidney Int 2004;66(3):1187-1192.

8. Mourant AE, Kopec AC, Domanewska-Sobczak K. The distribution of human blood groups and other polymorphisms. London Oxford University Press, p.140, 1976.

9. Cavasini et al. Duffy blood group genotypes among malaria patients in Rondônia, Western Brazilian Amazon. Rev Soc Bras Med Trop 2001;34(6):591-595.

10. Beiguelman B, Moura MM, Engracia V, et al. The association of genetic markers and malaria infection in the Brazilian Western Amazonian region. Mem Inst Oswaldo Cruz 2003; $98(4): 455-460$.

Prof. Adjunto do Depto. de Biologia Molecular da Faculdade de Medicina de São José do Rio Preto. Responsável pelo Laboratório de Imunogenética Molecular do Hemocentro de São José do Rio Preto. Pós-doutorado pelo Biotechnology Research Centre, Auckland University of Technology, Auckland, New Zealand.

Correspondência para: Luiz Carlos de Mattos Laboratório de Imunogenética Molecular - Hemocentro de São José do Rio Preto - Departamento de Biologia Molecular Faculdade de Medicina de São José do Rio Preto Avenida Brigadeiro Faria Lima, 5416 15090-000 - São José do Rio Preto-SP E-mail:luiz.carlos@famerp.br 